\title{
Incidence of cancer in the electronics industry: using the new Swedish Cancer Environment Registry as a screening instrument
}

\author{
D VÅGERÖ ${ }^{1}$ AND R OLIN ${ }^{2}$
}

From the Department of Social Medicine, ${ }^{1}$ Huddinge University Hospital, S-141 86 Huddinge, and the Preventive Occupational Medicine Unit, ${ }^{2}$ Department of Heat Technology, Royal Institute of Technology, Stockholm, Sweden

ABSTRACT The object of this study was to assess the relative risks of cancer for a particular branch of industry by using the newly created cancer environment registry. The registry was created by a record linkage of the 1960 census to the Swedish Cancer Registry 1961-73. A cohort study was undertaken of all subjects classified in the census as working in the electronics or electrical manufacturing industry. The risks were calculated in relation to the general working population. The results showed a slightly higher total incidence of cancer (all sites) in this branch of industry than in the general working population, for men as well as for women. This was especially so for tumour sites connected with the pharynx and the respiratory system. The study also indicates that the new registry has a potential as a screening instrument.

Health hazards in the electronics industry at large have rarely been reported. This may reflect a belief that this highly developed and rapidly changing branch of industry is not hazardous. The latest decennial supplement to the mortality statistics of England and Wales, however, found that the overall cancer mortality for electrical and electronic workers was slightly higher than expected. Also reported was a higher than expected morbidity for cancer of the mouth. ${ }^{1}$

Health hazards of relevance for the electronics industry have also been reported in connected branches or in subgroups of the industry. A particular case is electroplating. An American study ${ }^{2}$ suggested that the mortality rates for several cancers, particularly of the oesophagus and larynx, were higher than expected in the electroplating industry. In the British mortality statistics the occupational group of electroplaters was found to have a higher than expected proportional mortality ratio with regard to cancer of the intestine and cancer of the lung. The health hazards may be linked to processes of degreasing, grinding, polishing, and plating, as well as to others

This study was made possible by grants Nos $79 / 17$ and $80 / 244$ from the Swedish Work Environment Fund.

Received 24 March 1982

Accepted 7 May 1982 where exposure to organic solvents, acids, polychlorinated biphenyls, or metal fumes may occur. ${ }^{34}$ Soldering is another potential hazard and was recently pointed out as a possible cause of spontaneous abortions in a Finnish study of women in the electronics industry. ${ }^{5}$ Work-related respiratory diseases and occupational asthma have been linked to soldering in British studies. ${ }^{6-8}$ An unpublished American study (D B Winn et al) of women in the electronics industry suggests that there might be an excess risk of pharyngeal and oral cancers. Other occupations and sub-branches of the electronics industry or related to it may have other hazards, as suggested by Wertheimer and Leeper ${ }^{9}$ and by Davis. ${ }^{10}$

The electronics industry is a branch of industry not widely researched. It is appreciated that the electronics (or electrical manufacturing) industry contains several occupations and different working environments with different hazards, but it was thought feasible to screen the industry as a whole and, secondly, to screen the group of occupations classified as electronic or electrical work in this study.

The first objective of the study was to assess the excess risk of cancer, if any, for those working in the electronics or electrical manufacturing industry when compared with the working population in general. The second was to explore the potential of the cancer environment registry as a screening instrument. 


\section{Materials}

The Swedish Cancer Environment Registry contains in all some 385000 cases - that is, all cancers detected and reported between 1961 and 1973 in Sweden. ${ }^{11}$ Doctors in Sweden are in general obliged by law to report each tumour detected to the National Board of Health and Welfare, thereby providing that information to the Swedish Cancer Registry. The turnout rate has been shown to be very high. ${ }^{12}$

The linkage of the Swedish Cancer Registry to the 1960 population census was made possible by the Swedish system of personal identification numbers by which each person is assigned a unique number at birth, which is then the basis for the census as well as for many medical registries.

The 1960 census classified three subgroups as belonging to the electronics or electrical manufacturing industry (Swedish: Elektroindustri) - namely, the radio and TV industry, other electronics industryfor instance, telecommunications industry-and unspecified machine and electrical manufacturing industry. Results reported below refer to these taken as a whole, unless stated otherwise in the text.

The number of workers aged 15-64 classified as belonging to this branch of industry at the 1960 census was 54624 men and 18478 women: 1855 and 1009 cancers respectively were reported for these groups.

The cohort under study was compared with the general working population (all branches of industry and all occupations, age 15-64). This is the control population. It contained 2108952 men and 923723 women. The number of cancers was 82750 and 51939 respectively.

\section{Methods of analysis}

For each specific site, the cohort under study was compared with the control population of all workers. This was done for all ICD-codes 140-205 (on a three digit level, ICD 7th revision) as well as for the total number of cancers.
To measure the ratio of disease occurrence of the exposed to the unexposed the accumulated number of cases 1961-73 for both was used. In the analysis the data were stratified by age, sex, in most instances by county, and sometimes by social class. To summarise over strata, the Mantel-Haenszel estimator was used. ${ }^{13}$ This was interpreted as the relative risk. Confidence intervals were based on a method suggested by Miettinen. ${ }^{14}$ Men and women were studied separately. To test the hypothesis that the relative risk equals one, the Mantel-Haenszel test was used. ${ }^{13}$ The p-value was calculated and the test was two-sided. All instances when the hypothesis $R R=1$ were falsified using a 5\% significance level, controlling for age, are reported below.

\section{Results}

Comparing everyone employed in the electronics industry with the general working population, for men and women, the total cancer morbidity was significantly higher than expected. The difference, however, is modest. Relative risk estimates were found to be 1.15 for men and 1.08 for women. Controlling for region, however, the relative risk estimates were found to be 1.06 and 1.05 respectively.

Table 1 presents the relative risks, confidence intervals, and p-values for those sites where the null hypothesis of no difference was rejected, controlling for age.

Based on this screening, tumour sites connected to the mouth, the pharynx, and the respiratory systems were chosen for more detailed study. Table 2 presents the age-adjusted relative risks, the age and regionally adjusted relative risks, and in some occasions the age and social class adjusted relative risks for those sites.

Since these results refer to all employed (white and blue collar workers as well as management) and all branches of the electronics industry a separation of different categories was thought to be appropriate. This was done, but in general we were left with few tumours in each category, making the estimates

Table 1 Tumour sites, where RR significantly differed from 1 for all working in the electronics industry. Two-tailed test

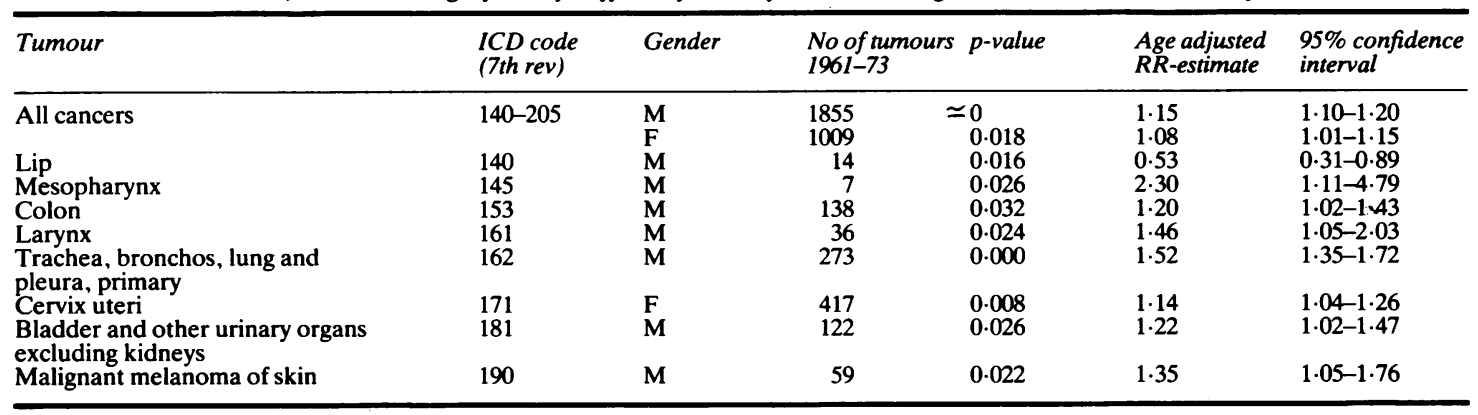


Table 2 Relative risk for tumour sites* connected to the mouth, pharynx, or respiratory system for all working in the electronics industry

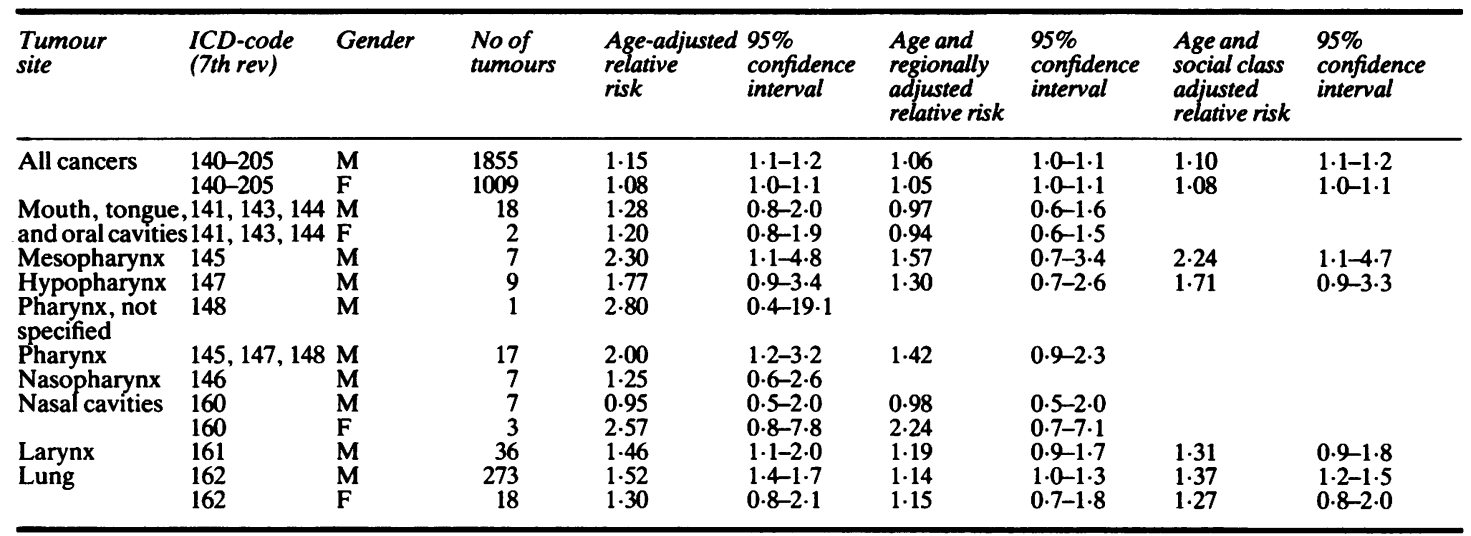

${ }^{*}$ Tumour sites where number of tumours were 1 or 0 are not reported here except for ICD-code 148.

Table 3 Relative risks for blue collar workers in the electronics industry. Selected sites

\begin{tabular}{|c|c|c|c|c|c|c|c|}
\hline Tumour site & $\begin{array}{l}\text { ICD-code } \\
\text { (7th rev) }\end{array}$ & Gender & $\begin{array}{l}\text { No of } \\
\text { tumours }\end{array}$ & $\begin{array}{l}\text { Age and } \\
\text { social class } \\
\text { adjusted } \\
\text { relative risk }\end{array}$ & $\begin{array}{l}95 \% \\
\text { confidence } \\
\text { interval }\end{array}$ & $\begin{array}{l}\text { Age, } \\
\text { regionally and } \\
\text { social class } \\
\text { adjusted } \\
\text { relative risk }\end{array}$ & $\begin{array}{l}95 \% \\
\text { confidence } \\
\text { interval }\end{array}$ \\
\hline $\begin{array}{l}\text { Mouth, tongue, and oral cavities } \\
\text { Pharynx } \\
\text { Larynx } \\
\text { Lung }\end{array}$ & $\begin{array}{l}141,143,144 \\
145,147,148 \\
161 \\
162 \cdot 0,162 \cdot 1\end{array}$ & $\begin{array}{l}\mathbf{M} \\
\mathbf{M} \\
\mathbf{M}\end{array}$ & $\begin{array}{r}10 \\
13 \\
20 \\
176\end{array}$ & $\begin{array}{l}1 \cdot 31 \\
2 \cdot 97 \\
1.46 \\
1 \cdot 36\end{array}$ & $\begin{array}{l}0 \cdot 7-2 \cdot 5 \\
1 \cdot 7-5 \cdot 1 \\
0 \cdot 9-2 \cdot 3 \\
1 \cdot 2-1 \cdot 5\end{array}$ & $\begin{array}{l}1 \cdot 00 \\
2 \cdot 03 \\
1 \cdot 12 \\
1 \cdot 13\end{array}$ & $\begin{array}{l}0.5-1.9 \\
1 \cdot 1-3.6 \\
0.7-1.8 \\
1 \cdot 0-1 \cdot 3\end{array}$ \\
\hline
\end{tabular}

Table 4 Relative risks for occupations classified as "other electronic workers." Tumour sites connected to the respiratory system, mouth, and pharynx

\begin{tabular}{|c|c|c|c|c|c|c|c|}
\hline Tumour site & $\begin{array}{l}\text { ICD-code } \\
\text { (7th rev) }\end{array}$ & Gender & $\begin{array}{l}\text { No of } \\
\text { tumours }\end{array}$ & $\begin{array}{l}\text { Age-adjusted } \\
\text { relative risk }\end{array}$ & $\begin{array}{l}95 \% \\
\text { confidence } \\
\text { interval }\end{array}$ & $\begin{array}{l}\text { Age and } \\
\text { regionally } \\
\text { adjusted } \\
\text { relative risk }\end{array}$ & $\begin{array}{l}95 \% \\
\text { confidence } \\
\text { interval }\end{array}$ \\
\hline Mouth, tongue, and oral cavities & $141,143,144$ & $\underset{\mathbf{M}}{\mathbf{M}}$ & 4 & 3.68 & $1.5-9.2$ & 2.98 & $1 \cdot 2-7 \cdot 6$ \\
\hline Pharynx & $145,147,148$ & $\begin{array}{l}\mathbf{M} \\
\mathbf{F}\end{array}$ & $\begin{array}{l}1 \\
1 \\
0\end{array}$ & $\begin{array}{l}1.50 \\
1.50 \\
0\end{array}$ & $\begin{array}{l}0.2-0 \cdot 0 \\
0.2-10 \cdot 5\end{array}$ & $\begin{array}{l}1.00 \\
1.17 \\
0\end{array}$ & $0 \cdot 2-8 \cdot 3$ \\
\hline Nasal cavities & 160 & $\begin{array}{l}\mathrm{M} \\
\mathrm{F}\end{array}$ & $\begin{array}{l}0 \\
3 \\
2\end{array}$ & $\begin{array}{l}5 \cdot 16 \\
4 \cdot 88\end{array}$ & $\begin{array}{l}1.9-14.3 \\
1.4-17.3\end{array}$ & $\begin{array}{l}5 \cdot 17 \\
4 \cdot 15\end{array}$ & $\begin{array}{l}1 \cdot 9-14 \cdot 3 \\
1 \cdot 1-15 \cdot 3\end{array}$ \\
\hline Larynx & 161 & $\begin{array}{l}\mathrm{M} \\
\mathrm{F}\end{array}$ & $\begin{array}{l}3 \\
0\end{array}$ & $\begin{array}{l}1.58 \\
0\end{array}$ & $0.5-4.8$ & $\begin{array}{l}1 \cdot 38 \\
0\end{array}$ & $0.4-4 \cdot 3$ \\
\hline Lung & $162 \cdot 0,162 \cdot 1$ & $\begin{array}{l}\mathbf{M} \\
\mathbf{F}\end{array}$ & $\begin{array}{r}25 \\
8\end{array}$ & $\begin{array}{l}1.83 \\
1.68\end{array}$ & $\begin{array}{l}1.2-2.7 \\
0.8-3.3\end{array}$ & $\begin{array}{l}1.48 \\
1.56\end{array}$ & $\begin{array}{l}1.0-2.2 \\
0.8-3 \cdot 1\end{array}$ \\
\hline
\end{tabular}

rather imprecise, as reflected in wide confidence intervals. Table 3 shows for some sites the relative risks for those classified as blue collar workers in this industry. Pharyngeal cancers in this group appear twice as often as expected.

When looking at the occupational classifications, one subgroup was found to have rather high relative risks for those sites discussed here. Table 4 shows the relative risks for "other electronic workers." This classification contains a more unqualified and machine-bound group of workers, preoccupied with assembly-type jobs.

Separating the different sub-branches of the industry again met the problem of small numbers of tumours. It was evident, however, that relative risks varied between, for instance, radio and TV industry and other electronics or electrical manufacturing industry. A particular case worth noting is 
nasopharyngeal cancers where the relative risk was 3.7 (confidence interval 1.0-13.5) in the radio and TV industry, controlling for age and region, while it was 1.0 in the other sub-branch.

\section{Discussion}

A slight excess risk of cancer, all sites, was found in the electronics industry as a whole. Blue collar workers in this industry had twice the risk of getting pharyngeal cancer compared with the working population in general. There may also be a slight excess risk of lung cancer. When separating different subcategories of the electronics industry or different subgroups of occupations classified as electronic workers in the 1960 census, certain clusters appeared, resulting in raised relative risks-for instance, for nasopharyngeal cancer among men employed in the radio and TV industry and cancer of the nasal cavities for other electronic workers.

Some methodological problems should be considered when interpreting the results. Firstly, studying the electronics industry as a whole presents us with various work environments and potential work hazards. This could dilute any statistical representation of a causal relationship between a particular feature of the work environment and a specific cancer. An estimated slight excess risk, referring to the electronics industry as a whole, could reflect some hazardous practice of a more severe type in some part of the industry.

Secondly, categories were formed on the basis of where people worked at the time of the 1960 census, rather than on the basis of their entire work history. This would again tend to dilute a casual relationship and underestimate the relative risk.

Thirdly, misclassifications of the branch of industry or occupation could occur. This has been studied in some detail. ${ }^{15}$ For those classified as working in the electronics industry in a reinterview of a random sample of the census, $98 \%$ were classified in the same way in the census. The reliability when subdividing categories was somewhat lower. It was also lower for occupational classifications. Misclassifications of this type would tend to underestimate the relative risk.

To avoid the "healthy worker effect" 1617 and selection bias the studied cohorts were compared with the general working population rather than with the whole population.

Risk estimates were generally adjusted for region, sometimes for social class, and in a few instances for region and social class simultaneously, to rule out these factors as confounders. Adjusting for region generally tended to give a lower relative risk estimate compared with when this was not done. Region here means county of residence, and there remains the possibility of a within-county variation of the urban/ rural factor. This could not be controlled for in this analysis. This could bias the relative risk estimate in any direction.

Respiratory, oral, and pharyngeal cancers are known to be linked to tobacco, snuff, and alcohol consumption. No data of this kind are known to the cancer environment registry. These factors could then confound the results. From a representative national survey undertaken in 1968 and 1974, however, we can estimate the fraction of smokers in different occupations and branches of industry. In fact, it was slightly lower in the machine and electronics industry than in other branches of industry (Stockholm Institute of Social Research, unpublished data). It would then seem less likely that the results presented above are due to confounding by smoking.

In this type of study there is also the problem of mass significance. Various solutions have been suggested to the problem of how to assess results based on significance testing in screenings such as ours. We have chosen to follow Cole ${ }^{18}$ and $O$ Miettinen (unpublished paper) - that is, to treat each individual significant correlation as equal to if it had been detected in a single statistical test. The crux of the matter seems to be how to deal with our statistical relationship vis-à-vis our a priori knowledge of the relation at hand. Results then modify the credibility or probability of a specific hypothesis based on previous knowledge.

Thus we conclude that the screening of the Swedish Cancer Environment Registry has suggested some new hypotheses to balance against the relatively scarce knowledge on risks in the electronics industry and electronic work. The observed excess risks of tumours connected to the pharynx and the respiratory system might indicate carcinogens transmitted by air. The obtained risk estimates, referring to the industry as a whole, do not seem likely to overestimate the actual risk.

It seems also that the Swedish Cancer Environment Registry has a potential for screening, but since the registry does not include any specific exposure data, risk estimates should be taken as starting points for further inquiry, focusing on particular features of the work environment.

\section{References}

1 Office of Population Censuses and Surveys. The Registrar General's decennial supplement for England and Wales, 1970 72. Occupational Mortality. London: HMSO, 1978.

${ }^{2}$ Blair A, Mason T. Cancer mortality in US counties with electroplating industries. Arch Environ Health 1980;35:92-4.

3 Yang M. Health hazards of electroplating. JOM 1965;7:348-52.

4 Talbott C, Hricko A. Hazards of the electronics industry. Monitor. 
Special issue. Berkeley: Institute of Industrial Relations, University of California, 1979.

${ }^{5}$ Hemminki K, Niemi K-L, Koskinen K, Vainio H. Spontaneous abortions among women employed in the metal industry in Finland. Int Arch Occup Environ Health 1980;47:53-60.

${ }^{6}$ Burge PS, Perks W, O'Brien IM, Hawkins R, Green M. Occupational asthma in an electronics factory. Thorax 1979;34:13-8.

${ }^{7}$ Perks WH, Burge PS, Rehahn M, Green M. Work-related respiratory disease in employees leaving an electronics factory. Thorax 1979;34:19-22.

${ }^{8}$ Burge PS, O'Brien IM, Harries MG. Peak flow rate records in the diagnosis of occupational asthma due to colophony. Thorax 1979;34:308-16.

9 Wertheimer N, Leeper E. Electrical wiring configurations and childhood cancer. Am J Epidemiol 1979;109:273-84

${ }^{10}$ Davis JM. Bladder tumours in the electric cable industry. Lancet 1965;ii:143-6.

11 National Board of Health and Welfare, the National Central Bureau of Statistics, and the Swedish Work Environment Fund Swedish Cancer Environment Registry 1961-1973. Stockholm:
1980.

12 Mattsson B. Completeness of registration in the Swedish Cancer Registry. Stockholm: National Central Bureau of Statistics, 1977. (Statistical reports, HS 1977:15.)

${ }^{13}$ Mantel M, Haenszel W. Statistical aspects of the analysis of data from retrospective studies of disease. Nat Cancer Inst 1959;22: $719-48$.

${ }^{14}$ Miettinen O. Estimability and estimation in case referent studies. Am J Epidemiol 1976;103:226-35.

${ }^{15}$ Brivkalne M. The control study made in connection with the 1960 census of population. Stockholm: National Central Bureau of Statistics, 1964. (Statistical report B 1964:16.)

${ }^{16}$ Goldschmidt JR. What do we expect from an occupational cohort? JOM 1975;17:126-7.

${ }^{17}$ Fox AJ, Collier PF. Low mortality rates in industrial cohort studies due to selection for work and survival in the industry. $\mathrm{Br} J$ Prev Soc Med 1976;30:225-30.

${ }^{18}$ Cole P. The evolving case control study. J Chronic Dis 1979;32:1527. 